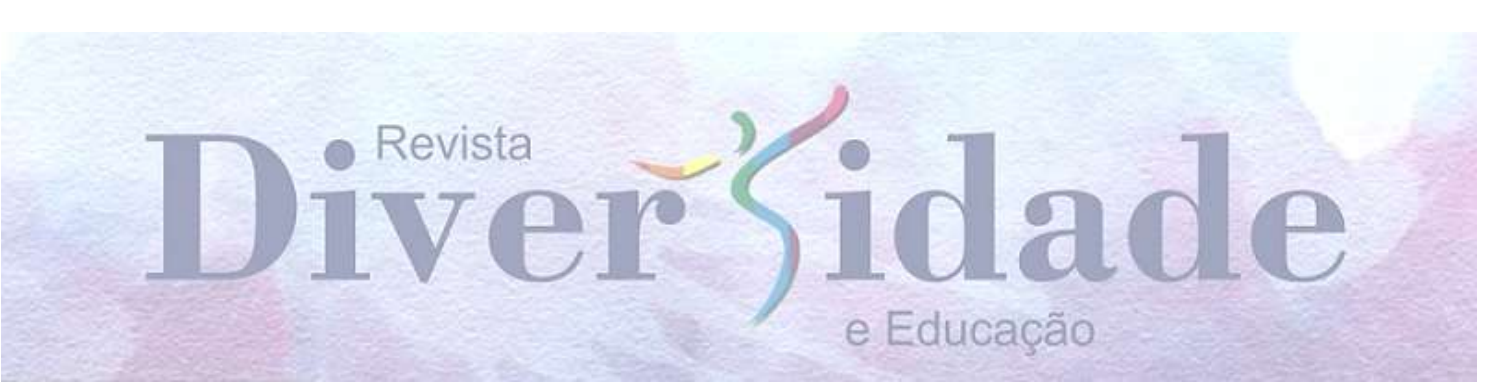

\title{
O RACISMO ESTRUTURAL E A VIDA ESCOLAR - UMA REFLEXÃO GEOGRÁFICA
}

\author{
EL RACISMO ESTRUCTURAL Y LA VIDA ESCOLAR - UNA REFLEXIÓN \\ GEOGRÁFICA
}

\section{STRUCTURAL RACISM AND THE LIFE IN SCHOOL - A GEOGRAPHICAL THOUGHT}

\author{
Isaías de Araújo Canuto ${ }^{1}$ \\ Mikaella Manso Macedo Tavares ${ }^{2}$ \\ Leonardo Biage de Andrade ${ }^{3}$ \\ Gisele Barbosa dos Santos ${ }^{4}$
}

\section{RESUMO}

Este trabalho é fruto da atuação do Pibid-Geografia da UFJF na Escola Estadual Governador Juscelino Kubitschek, entre os anos de 2018 e 2020. As intervenções tiveram como pauta o racismo estrutural e seus reflexos no espaço escolar. A pesquisa desenvolveu-se por meio de leituras e reflexões de textos, canais de comunicação digital, estudo de leis, oficinas (vídeos, músicas, desenhos e jogos) sobre o racismo no cotidiano e no processo histórico brasileiro. Após práticas de cunho pedagógicoreflexivo, percebeu-se o amadurecimento dos estudantes ao lidarem com o tema, bem como, avultou importância dos estudos geográficos para a compreensão do espaço em diferentes escalas sob uma perspectiva de construção histórica, política e social. Isso indica mais um avanço realizado em relação à inserção das discussões sobre as temáticas raciais na escola, resgatando as origens do preconceito, da discriminação e do racismo, apontando novas perspectivas de luta, de inserção e de criticidade frente às desigualdades raciais.

PALAVRAS-CHAVE: Relações étnico-raciais. Pibid. Equidade racial. Resistência.

\footnotetext{
${ }^{1}$ Universidade Federal de Juiz de Fora.

${ }^{2}$ Universidade Federal de Juiz de Fora.

${ }^{3}$ Secretaria Estadual de Educação de Minas Gerais.

${ }^{4}$ Professora Adjunta do Departamento de Geociências (DEGEO) da Universidade Federal de Juiz de Fora (UFJF). Doutora em Ciências Naturais (Geologia Ambiental e Conservação de Recursos Naturais), pelo Programa de Pós-Graduação em Evolução Crustal e Recursos Naturais da Universidade Federal de Ouro Preto.
} 


\section{RESUMEN}

Este trabajo es fruto de la actuación del Programa Institucional de Becas de Iniciación a la Docencia-PIBID-Geografía de la Universidad Federal de Juiz de Fora-UFJF en la Escuela Estadual Gobernador Juscelino Kubitschek, entre los años de 2018 e 2020. Las intervenciones tuvieron como pauta el racismo estructural y sus reflejos en el espacio escolar. La búsqueda por medio de lecturas y reflexiones de textos, canales de comunicación digital, estudio de leyes, talleres (videos, músicas, dibujos, juegos) sobre el racismo en el cotidiano y en el proceso histórico brasileño. Tras prácticas de cuño pedagógico-reflexivo, se ha percibido el grado de madurez de los estudiantes al hacer frente con el tema, así como, es necesario destacar la importancia de los estudios geográficos para la comprensión del espacio en diferentes escalas acerca de una perspectiva de construcción histórica, política y social. Señalando, más un avanzo realizado en relación a la inserción de las discusiones al tratar de las temáticas raciales en la escuela, rescatando los orígenes del prejuicio, de la discriminación y del racismo, apuntando nuevas perspectivas de lucha, de inserción y de criticidad delante de las desigualdades raciales.

PALABRAS-CLAVE: Relaciones étnico-raciales. Pibid. Igualdad racial. Resistencia.

\section{ABSTRACT}

This work results from UFJF's Pibid-Geography (a Scholarship Program of the Federal University of Juiz de Fora) at Governor Juscelino Kubitschek Elementary and High School, from 2018 to 2020. The interventions have focused on the structural racism and its reflections at school environment. The research has been developed by readings and text comprehension, digital communication channels, studies of laws and workshops (videos, music, games, and drawings) about racism in daily life and in the Brazilian historical process. After pedagogical-reflective practices, it was noticed the students' maturity by dealing with such issue as well as showing how important is the geographical studies for the comprehension of the space in different scales under a perspective of social, political and historical construction, pointing to another progress related to the discussions about the racial themes at school, bringing back the origins of prejudice, discrimination and racism, but pointing out new perspectives of fight, insertion and criticism against racial inequalities.

KEYWORDS: Ethnic-racial relations, Pibid (Scholarship Program), Racial Equality, Resistance.

$* * *$

\section{Introdução}

O espaço escolar é um rico palco para as reflexões das diferenças tendo em vista a diversidade cultural presente, a qual reflete o bojo da sociedade que está inserida. Este trabalho é fruto da atuação do Pibid-Geografia-UFJF, que esteve presente na Escola Estadual Governador Juscelino Kubitschek, desde agosto de 2018 até janeiro de 2020. O Programa de Iniciação à Docência (Pibid) tem como finalidade inserir os graduandos de licenciatura no ensino básico desde os períodos iniciais da graduação a fim de 
promover uma melhor interação entre academia e escola básica, proporcionado uma melhor formação docente.

A escola Estadual Governador Juscelino Kubitschek localiza-se na região sul da cidade de Juiz de Fora, entre o bairro Santa Luzia e o bairro Estrela Sul. Ela atende alunos de vários bairros como Bela Aurora, Sagrado Coração, Ipiranga, Santa Efigênia, Santa Cecilia e Santa Luzia. Conforme apresentado no trabalho de Silva et al., (2020) a maioria dos estudantes desta escola são moradores de bairros de classe social baixa, e a escola se localiza no limite entre um bairro que reflete essas condições e um bairro de classe média alta, com melhores condições de infraestrutura. A partir da observação dos Pibidianos, foi constatado que a maioria dos alunos são negros, e que o racismo é uma prática recorrente dentro do ambiente escolar. Muitas vezes, aflorado em forma de brincadeira ou humilhação, para coagir determinado aluno, mesmo entre os alunos negros. Essa prática, que se perpetua no ambiente escolar, normalizado em práticas cotidianas recebe o nome de Racismo Recreativo, definido por Moreira (2019):

Ele deve ser visto como um projeto de dominação que procura promover a reprodução de relações assimétricas de poder entre grupos raciais por meio de uma política cultural baseada na utilização do humor como expressão e encobrimento de hostilidade racial. (Moreira, 2019, p. 95)

Ao vivenciar a rotina das turmas, durante as aulas e analisando o comportamento dos alunos em geral, que relataram sofrer racismo também fora do ambiente escolar, os Pibidianos tiveram o interesse em introduzir temas transversais à Geografia, como é o caso do racismo e sua estruturação histórico-geográfica nas pautas das aulas, sendo considerado como de extrema relevância para esta comunidade estudantil. Houve uma boa aceitação e o interesse por parte dos alunos em discutir e refletir sobre o tema, pois muitos deles já vivenciaram práticas racistas.

Segundo Gomes (2002) na instituição escolar, assim como na sociedade, o corpo é uma forma de comunicação, pois é construído biologicamente e simbolicamente na cultura e na história, sendo capaz de demarcar nossa localização na sociedade pela sua mediação no espaço e no tempo, neste sentido salienta que "o cabelo e a cor da pele podem sair do lugar da inferioridade e ocupar o lugar da beleza negra, assumindo uma significação política" (GOMES, 2002, p.49).

Esta é uma importante reflexão visto que, muitos meninos e meninas da escola utilizavam o cabelo black power, importante símbolo do movimento negro dos anos 
1960 (SANTOS; SANTOS, 2018) e camisas de líderes negros, mas diante de várias atitudes racistas observadas, emergiu a questão sobre a legitimidade do uso da moda e da estética como ferramentas políticas e ressignificação do corpo negro.

A partir das questões aventadas, a atuação do Pibid se pautou na temática racial com foco em debates e atividades, a fim de promover uma maior reflexão por parte dos educandos sobre o seu cotidiano e o processo de desconstrução de estereótipos raciais e valorização da cultura afro-brasileira no âmbito das aulas de Geografia.

\section{Evolução da Temática Racial na Educação Brasileira}

Mesmo depois de 132 anos da abolição da escravatura, nos dias atuais a população negra fruto desse processo histórico-geográfico ainda não alcançou a equidade racial na sociedade brasileira (SANTOS, 2009).

Em relação à educação, por exemplo, uma pesquisa nacional por amostra de domicílios (PNAD, 2015) constatou que $45,22 \%$ da população se autodeclara branca e $54,78 \%$ se autodeclara preta parda ou indígena. Mas em contrapartida, por exemplo, a população negra representa apenas $12,8 \%$ dos universitários brasileiros. Na questão do analfabetismo, para pessoas com mais de 15 anos os negros representam 9,1\% enquanto que os brancos representam 3,9\%. Mas esses dados são recentes, ou seja, os números eram ainda menos expressivos, por exemplo, em 2005 quando os negros representavam apenas 5,5\% dos estudantes universitário brasileiros. Esse aumento provavelmente pode estar atrelado à política de cotas raciais (IBGE, 2016).

De acordo com Jaccoud (2008) é nos anos 2000 que as políticas públicas, nas esferas municipal, estadual e federal, ganham robustez, principalmente via e estabelecimento de cotas, visando ampliar o acesso de estudantes negros ao Ensino Superior, bem como programas de combate ao racismo institucional.

No que diz respeito à inserção de temáticas da cultura Africana e Afro-brasileira nas escolas do Brasil, destaca-se a lei 10.639/2003, que tem como objetivo contrapor o até então processo de ensino brasileiro, que em muitas vezes se mostrava unilateral, branco e eurocêntrico (OLIVEIRA, 2011), propondo a inclusão não só dos negros, mas também dos povos indígenas como agentes de processos históricos, da mesma forma que os povos europeus (COELHO; COELHO, 2013). Esta lei é fruto do engajamento do movimento negro, de intensa luta política, cujas demandas só foram incluídas após 
trinta anos por meio de sua promulgação e implantação no sistema educacional (SOUZA, 2009).

Pôde-se então, vislumbrar um futuro mais promissor quanto ao ensino da cultura afro-brasileira no chão da escola. Pois, de acordo com Santos (2009) a lei insere o debate racial nas escolas básicas, que ficavam fora dessa discussão. Dessa forma, podese construir ou programar ideias, conceitos, projetos sociais, aulas voltadas para a temática racial com os alunos, a fim de promover um conhecimento mais amplo nos educandos sobre o processo de formação histórico-geográfico que culminou nessa extraordinária população brasileira, indo além, essas ações tem como objetivo colocar o negro como um agente da construção cultural do país.

Ao se tratar das questões curriculares da escola básica, a Base Nacional Comum Curricular (BNCC) pouco avança nessa temática racial, a palavra "racismo" pouco aparece nos documentos referentes ao Ensino de História, não sendo nem mencionada no Ensino de Geografia (BRASIL, 2017). Ferreira (2015) traz uma reflexão sobre o tema diversidade que está relacionado diretamente com racismo aplicado à base

Aplicado ao currículo nacional, o conceito de diversidade não pode ser apenas um jargão, porque incorporar esse conceito sem fundamentá-lo teoricamente, ou apenas como um conteúdo curricular ou tema transversal, significa esvaziá-lo e reduzi-lo à retórica política (FERREIRA, 2015, p. 307).

Dessa forma, caberá ao professor de Geografia encontrar temas que se articulem na BNCC, respaldando-se na lei 10.639/2003, com as temáticas raciais. Por exemplo, nas "unidades temáticas da BNCC: "sujeito e seu lugar no mundo", "mundo do trabalho" e "conexões e escalas" o professor percebendo a necessidade da turma conseguirá encaixar a temática racial.

\section{Geografia e questões étnico-raciais}

Estudar Geografia é estudar o espaço-tempo das ações da humanidade. Assim sendo, o conceito de raça possui um caráter geográfico, em uma perspectiva histórico-geográfica, pois as relações de poder e hierarquia social foram construídas ao longo dos séculos e os processos geográficos estão ligados a esse fator (SANTOS, 2009). 
No Brasil a Geografia está diretamente ligada à questão racial, seja nos estudos demográficos, nos estudos de comunidades quilombolas, ou então na própria Geografia Escolar, onde a questão racial pode e deve ser explorada. Como nos diz Santos (2007), a função da Geografia é proporcionar para as pessoas:

(i) conhecer sua posição no mundo, e para isto o indivíduo precisa conhecer o mundo; (ii) tomar posição neste mundo, que significa se colocar politicamente no processo de construção e reconstrução desse mundo. Se posicionar no mundo é, portanto, conhecer a sua posição no mundo e tomar posição neste mundo, agir. Saber Geografia é saber onde você está, conhecer o mundo, mas isto serve fundamentalmente para você agir sobre esse mundo no processo de reconstrução da sociedade: se apresentar para participar (SANTOS, 2007, p. 27).

A Base Nacional Comum Curricular nos traz que Geografia é:

Uma oportunidade para compreender o mundo em que se vive, na medida em que esse componente curricular aborda as ações humanas construídas nas distintas sociedades existentes nas diversas regiões do planeta. Ao mesmo tempo, a educação geográfica contribui para a formação do conceito de identidade, expresso de diferentes formas: na compreensão perceptiva da paisagem, que ganha significado à medida que, ao observá-la, nota-se a vivência dos indivíduos e da coletividade; nas relações com os lugares vividos; nos costumes que resgatam a nossa memória social; na identidade cultural; e na consciência de que somos sujeitos da história, distintos uns dos outros e, por isso, convictos das nossas diferenças (BRASIL, 2017, p. 359).

Ou seja, a Geografia se apresenta como possibilidade de proporcionar aos estudantes compreender o espaço-tempo em que ele está vivendo, fazer conexões com o passado para entender os problemas sociais no espaço-tempo presente, tornando-se assim um ser político e crítico.

No caso da experiência aqui relatada, as conexões da Geografia com o espaço vivido pelos estudantes foram levadas em consideração para interferir na temática racial que emergiu durante as aulas, buscando contrapor o que relata Santos (2009), em relação à questão racial nas escolas, alertando para o problema da omissão de alguns professores diante de situações ligadas a essa temática.

Este mesmo autor explicita que alguns temas centrais da Geografia se fazem presentes no debate de equidade racial "O debate raça \& modernidade, O ensino sobre África, As Comunidades Remanescentes de Quilombos, A Segregação Sócio Espacial nos meios urbanos, Espacialização de dados sobre desigualdades raciais, As 
"Experiências de Espaço" de diferentes indivíduos e grupos". Ele ainda completa dizendo que esses tópicos são alguns de muitos outros que podem existir.

Sendo tão vastos os campos e temas que abordam a temática racial na Geografia, recomenda-se começar estes estudos com alunos do $6^{\circ}$ ano do Ensino Fundamental, que possuem uma grande jornada escolar pela frente para poderem construir um senso crítico e questionador.

A educação, tão pouco a Geografia (sozinha) conseguirá mudar a visão de mundo eurocêntrica que circula nos livros didáticos trazendo a África como algo único e homogêneo e atrasado (OLIVEIRA, 2011). No entanto, a Geografia tem muito a contribuir na luta contra essa visão hegemônica. A começar pela quebra dessa visão monolítica do continente africano quando trabalha as questões de conexões e escalas globais. Ao trabalhar a formação cultural do povo brasileiro o papel do negro escravizado necessita ser abordado, sendo vastas as possibilidades de temas que a Geografia domina para auxiliar no processo de uma educação mais democrática.

A Geografia vem evoluindo muito no campo dos estudos da cultura afrobrasileira como descreve Santos (2014), em uma pesquisa que aponta mais de 50 estudos de mestrado, doutorado e projetos de pesquisa na área. Como consequência essa nova temática está chegando à educação básica.

\section{A educação e o racismo na escola}

Freire (1983) diz que a identidade cultural é algo herdada e construída pelos educandos, dessa maneira ao inserimos a temática racial no ambiente escolar estamos de certa forma construindo, por mais que seja de uma maneira introdutória, junto com os alunos uma cultura de equidade racial. Nesta mesma linha Oliveira (2011) destaca que a escola é produtora de conhecimento, e é local privilegiado para se desenvolver o diálogo a respeito do preconceito racial. Dessa forma, ao se observar práticas racistas no cotidiano escolar, faz-se necessário intervir, para produzir um ambiente de debate, como se espera de uma educação não bancária e para a liberdade.

O racismo é algo complexo, no entanto foi adotado neste trabalho, duas definições sobre este tema que sintetizam o que foi presenciado em sala de aula, a falta de pertencimento por parte dos alunos a ponto de haver entre eles insultos raciais, mesmo os próprios sendo negros e tendo passado por discriminação, dando margem à 
interpretação de que essa prática se faz tão enraizada na sociedade que o sentimento de subalternidade às vezes parece "normal".

Trindade (2002) conceitua o racismo pela fala de Amauri Mendes Pereira (Militante do Movimento Negro) como sendo:

[...] uma ideologia de dominação servindo a raça e classe dominante, que desmobiliza, inibe e em muitos casos destrói a identidade cultural do nosso povo. Isso ocorre através de formas de controle institucional de mecanismos de reprodução cultural e imposição de valores e de representações distorcidos que se acumulam no dia-a-dia da grande maioria da população (TRINDADE, 2002, p. 19).

O estatuto de igualdade racial com base na lei $\mathrm{n}^{\circ} 12.288$ de 2010 define discriminação racial no artigo $1^{\circ}$ parágrafo único como:

Discriminação racial ou étnico-racial: toda distinção, exclusão, restrição ou preferência baseada em raça, cor, descendência ou origem nacional ou étnica que tenha por objeto anular ou restringir o reconhecimento, gozo ou exercício, em igualdade de condições, de direitos humanos e liberdades fundamentais nos campos político, econômico, social, cultural ou em qualquer outro campo da vida pública ou privada (BRASIL, 2014, p. 3).

Quando os alunos do sexto ano da Escola Estadual Juscelino Kubitschek foram questionados sobre o que era racismo surgiram falas muito interessantes como: "Racismo é não gostar do outro porque a pessoa é diferente" ou "Racismo é não gostar da cor da outra pessoa".

Os alunos sabem o que é racismo em termos gerais e sabem que é errado, no entanto entre eles, muitas vezes, não acontece uma percepção de que algumas falas e atitudes entre os colegas de classe estão embutidas o racismo.

Freire (1983, p. 64) diz que "a transformação do mundo material, das estruturas materiais a que se junte simultaneamente um esforço crítico-educativo é o caminho para a superação, jamais mecânica, dessa herança”. Logo a educação é uma força contra o racismo, obviamente, sendo trabalhada com demais setores da sociedade.

Sob uma perspectiva geográfica espacial da escola, para além de um local de socialização, percebe-se que as interações sociais que ocorrem na escola são resultantes da interação dos alunos e o espaço escolar. Ali eles estão formando suas visões de mundo, criando hábitos, sentimentos de pertencimento com o espaço escolar em si, mas também com mundo (MARQUES, 2013).

O artigo 205 da constituição brasileira de 1988 aponta que, 
A educação, direito de todos e dever do Estado e da família, será promovida e incentivada com a colaboração da sociedade, visando ao pleno desenvolvimento da pessoa, seu preparo para o exercício da cidadania e sua qualificação para o trabalho (BRASIL, 1988, p. 123).

Logo se faz necessário inserir a temática racial no cotidiano escolar para que o processo de escolarização tenha o debate racial como um dos diversos temas. Segundo Malachias (2006) na ótica geográfica as questões étnico-raciais poderiam ser destacadas em duas escalas, sendo uma de caráter continental e civilizatório, onde a Europa é homogeneizada como grupo racial superior, e uma segunda teria caráter essencialista, que pluraliza etnicamente as nacionalidades políticas, segundo suas funções históricas, culturas, tradições, feitos e símbolos "comuns" ao país ou coletividade em questão. Neste trabalho partimos da premissa da segunda escala mencionada, onde as questões políticas foram tratadas como relações de pertencimento da coletividade da escola.

O racismo no Brasil possui um caráter estrutural, ou seja, integra a organização econômica e política da sociedade de forma inescapável (ALMEIDA, 2019). Lins; Lima; Camino (2014) apontam que o preconceito racial é uma configuração de consciência social resultante de situações históricas concretas das relações intergrupais, como uma forma de dominância. Neste sentido podemos refletir como o preconceito em relação aos negros no Brasil vem sendo alimentado desde a época colonial, quando pessoas eram tratadas como mercadoria e vistas como forma de lucrar por aqueles que se sentiam no direito de determinar quem era pessoa e quem era objeto.

Visto que o Pibid é um projeto voltado para educação, é salutar analisarmos os dados disponibilizados pelo IBGE por intermédio da PNAD (Pesquisa Nacional por Amostra de Domicílios) sobre os indicadores educacionais por cor ou raça nas Grandes Regiões.

Observando-se a Figura 1a, pode-se perceber nos dados quantitativos que há um déficit na vida escolar dos jovens negros e pardos em relação aos brancos, em todos os índices apresentados. Estes dados mostram que, mesmo nos dias atuais, ainda persistem a herança da educação no período colonial, que de acordo com Silva e Araújo (2005) gerou para esta população um triste legado, o qual denominam "interdição à educação formal".

Portanto, é preciso enxergar a escola como palco de reflexões sobre esse triste legado e, ao mesmo tempo, inclusiva. As iniciativas do Pibid, que se configura como um programa de integração entre universidade-escola com um intuito de formação de 
professores, pressupõe voltar seu olhar para práticas que possibilitem eliminar os efeitos persistentes das barreiras impostas no passado, acolher os estudantes fruto de políticas educacionais voltadas para dirimir tais distâncias, refletir sobre lutas e militância dos negros para o acesso à educação como configuração política racial, resultando em reconhecimento e destaque dos negros na construção da sociedade brasileira.

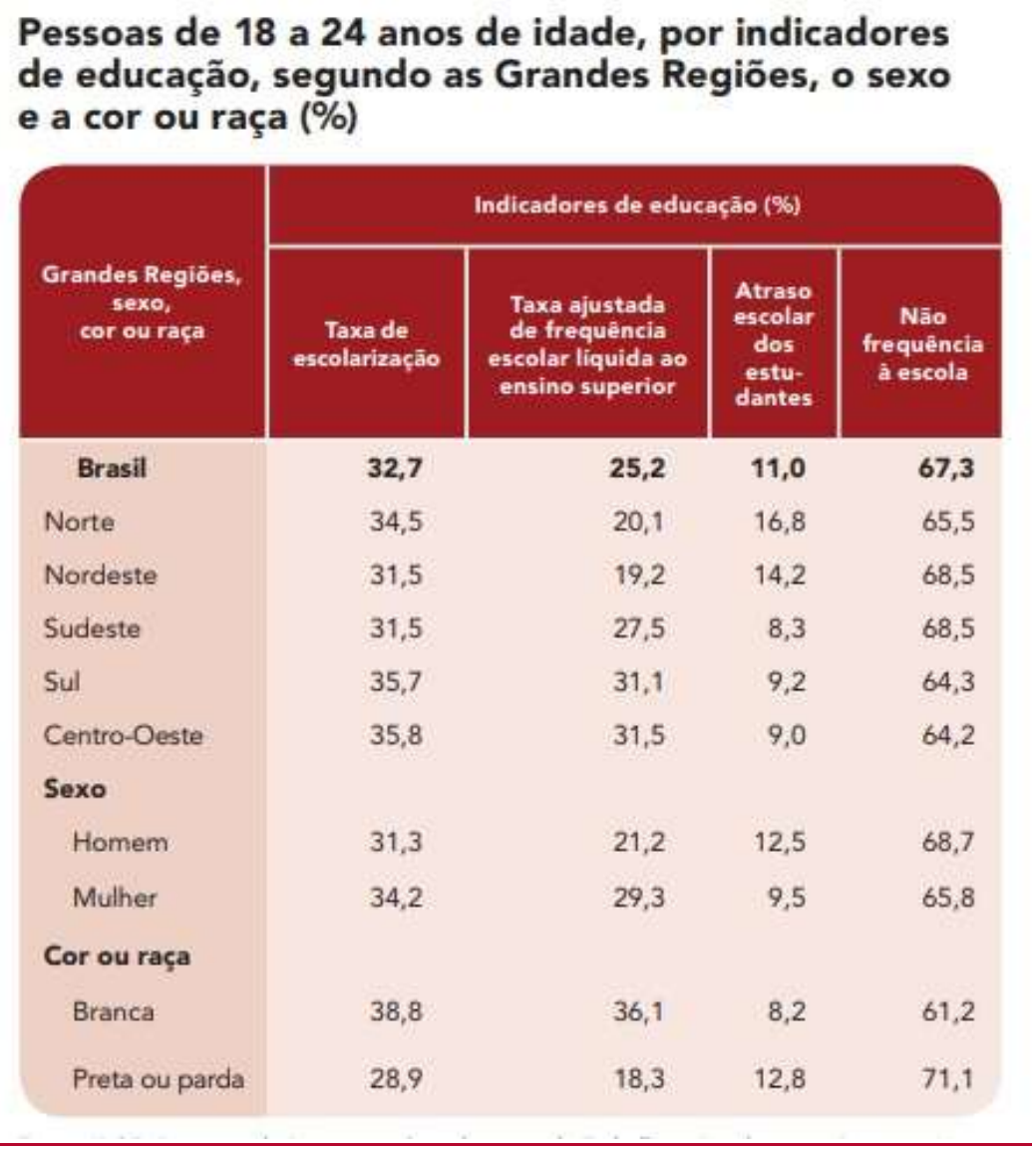

Figura 1: Fonte: IBGE (2019, p.

8)https://biblioteca.ibge.gov.br/visualizacao/livros/liv101657_informativo.pdf 


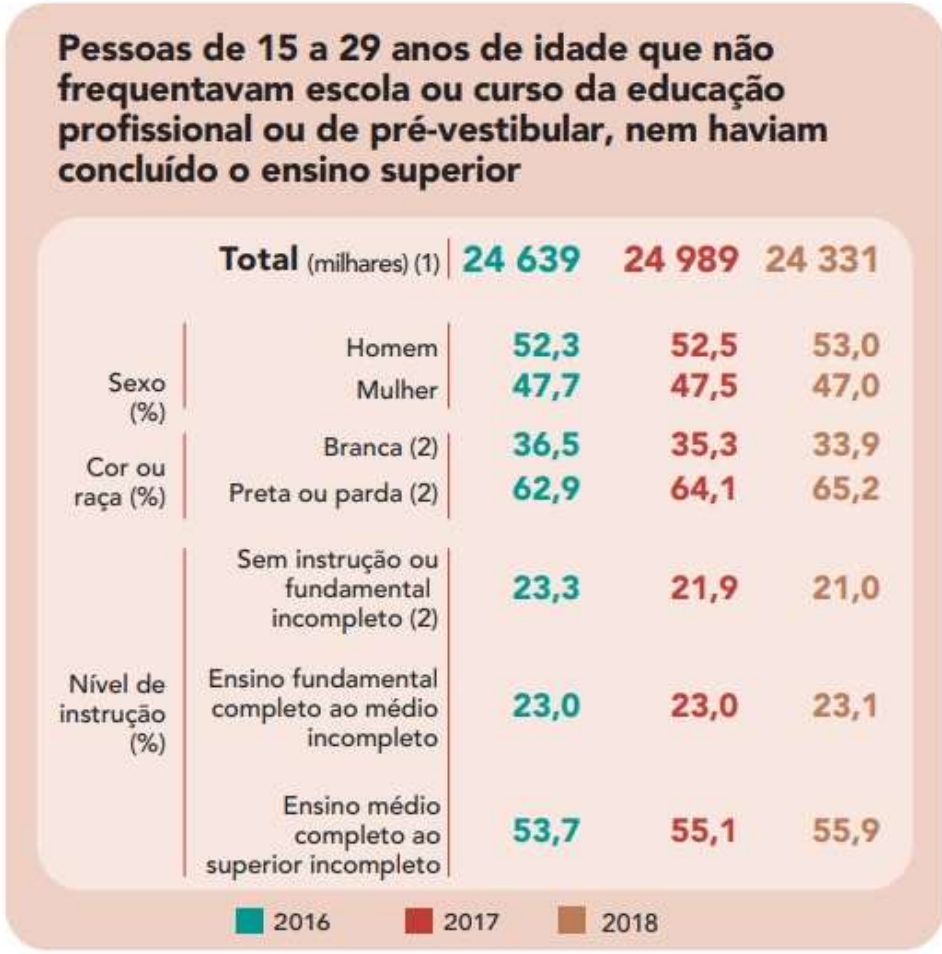

Figura 2: Fonte: IBGE (2019, p. 11)

https://biblioteca.ibge.gov.br/visualizacao/livros/liv101657_informativo.pdf

A figura 2 evidencia os baixos índices de ampliação da qualificação acadêmica da população brasileira entre os anos de 2016 a 2018. O que chama atenção nos dados é que os índices de pessoas negras e pardas entre 15 a 29 anos no período citado que não dão continuidade aos estudos após o ensino médio é praticamente o dobro em relação à população branca.

Diante desses dados, a atuação do Pibid na escola procurou fomentar o interesse dos estudantes para a continuidade nos estudos, aproximando-os da realidade desses dois grupos de estudantes: Pibidianos e estudantes do Ensino Básico. Também estimulou-se a leitura do espaço geográfico, político e social da coletividade da escola, buscando o fortalecimento de um debate lúcido, em defesa da sociedade brasileira que vise uma democracia racial.

\section{Relato de experiência: Ações do Pibid na Escola}

As ações aqui relatadas foram realizadas em duas turmas do sexto ano durante o ano letivo de 2019. Uma das turmas era composta por 32 alunos, com idades entre 11 e 
13 anos, ou seja, dentro da faixa etária prevista. A outra turma era composta por 24 alunos, com idades entre 11 e 15 anos, portanto heterogênea.

Além da heterogeneidade de faixa etária, a segunda turma se enquadra dentro dos moldes definidos por Hess (2001), diferindo também quanto à motivação, autodisciplina, atitudes, e interesses. Cabe aqui ressaltar a prática ConstrutivistaFreireana que visa promover uma abordagem não baseada na simples transferência de conhecimento, mas na investigação, na experimentação e no resgate e valorização do conhecimento prévio dos estudantes (FREIRE, 1983).

Diante deste cenário buscou-se uma gama de atividades envolvendo temáticas étnico-raciais, onde os pibidianos e o supervisor pudessem assumir o papel de colaboradores, incentivando os estudantes a interagirem verbalmente, a fim de resolver as tarefas de reflexão e aprendizagem em comum.

Dentro dessa proposta, o tema foi abordado da seguinte maneira:

\section{a) Organização do jogo do privilégio branco}

O Instituto Identidades do Brasil $^{5}$ criou essa dinâmica buscando que as pessoas entendessem, na prática, as vantagens raciais e como acontece a distribuição de privilégios na nossa sociedade. Segundo os criadores é um jogo onde os próprios participantes são as peças que se movem de acordo com suas histórias de vida. Visto isso, esse jogo foi escolhido para que os alunos vissem de forma clara e simples como funciona o racismo na sociedade e como há raças com vantagens sobre outras.

Para a realização da dinâmica, os alunos foram levados para a quadra da escola, e colocados todos em uma fileira no meio da quadra, de maneira que ficassem um ao lado do outro. Então, começou-se a aplicação do roteiro selecionado e de acordo com cada afirmação, eles deveriam dar um passo à frente, ou um passo para trás, de acordo com correspondência com sua realidade.

Para o jogo do privilégio branco foram selecionadas 31 afirmativas, capazes de demonstrar na prática as vantagens raciais e como acontece a distribuição de privilégios na nossa sociedade (Quadro 1).

${ }^{5}$ O Instituto Identidades do Brasil (ID_BR) é uma organização sem fins lucrativos, pioneira no Brasil e $100 \%$ comprometida com a aceleração da promoção da igualdade racial. Disponível em: http://simaigualdaderacial.com.br/site/ 
Quadro 1: Perguntas jogo do privilégio.

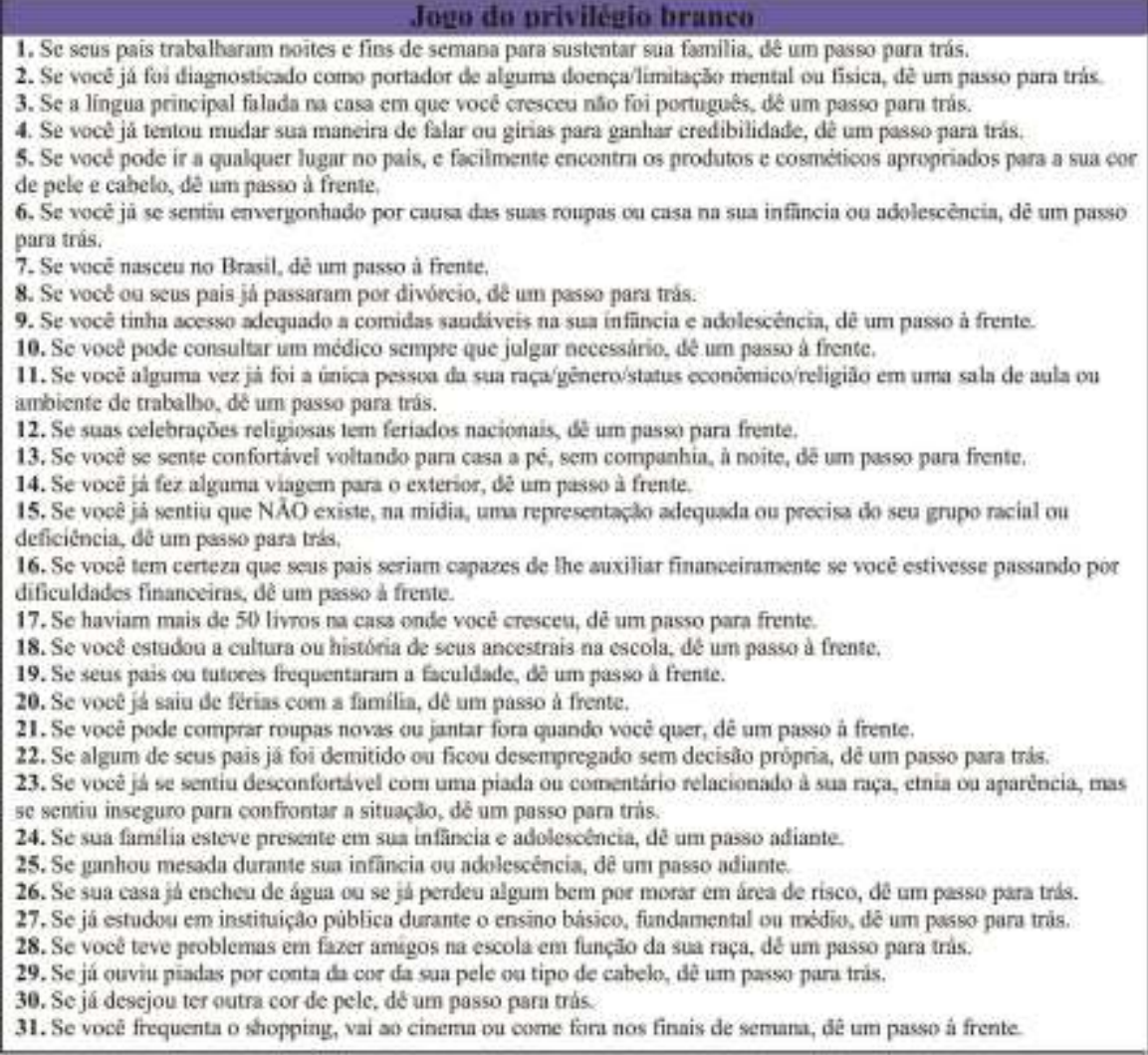

Fonte: Adaptado de http://simaigualdaderacial.com.br/site/

Ao término do jogo, o posicionamento dos estudantes se mostrou bastante variado como ilustra a figura 2 . Os estudantes foram estimulados a refletirem sobre como aquele arranjo, de certo modo refletiam seus posicionamentos situações do cotidiano de suas vidas na sociedade.

FIGURA 2: Alunos posicionados para a atividade.

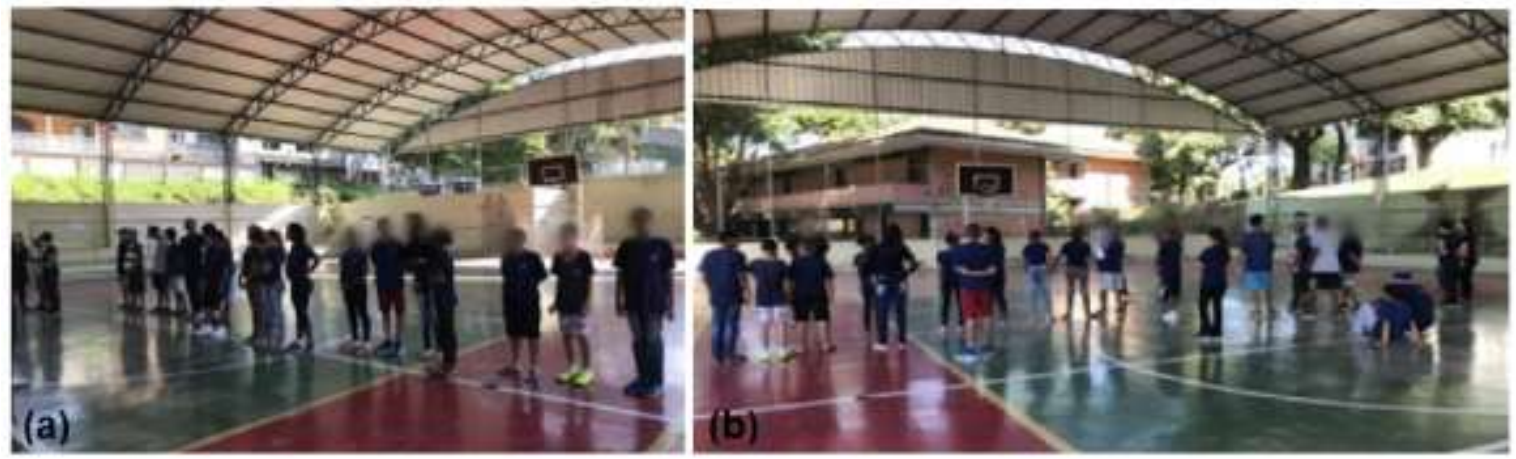

Fonte: Os autores, maio de 2019.

Os estudantes puderam perceber que o arranjo ao final do jogo reproduziu o padrão da sociedade, baseando-se no posicionamento dos alunos negros, que ficaram 
em desvantagem em relações aos alunos brancos, refletindo o racismo estrutural que está presente na sociedade.

Uma das afirmativas que mais chamou a atenção foi o passo atrás da maioria dos alunos negros e com idade mais avançada, ao serem indagados sobre já terem sido abordados em ações policiais em algum momento da vida, e que a princípio este fato não foi visto com estranheza pelos estudantes. Esta constatação corrobora com o panorama, em três capitais brasileiras, enunciado por Anunciação; Trad; Ferreira, (2020, p.1) onde a "segregação racial e o racismo, mostraram-se presentes na estrutura e dinâmicas relacionais da sociedade brasileira, assim como sua negação e/ou certa naturalização, influenciam a "tomada de decisão" e o modo de atuar da polícia frente à juventude".

Outros fatos perceptíveis foram que, de maneira geral, os pais dos alunos trabalham até mesmo no final de semana. Outro elemento, que pode ser contextualizado naótica Geografia Urbana, foi o fato de que a maioria dos estudantes negros não frequenta espaços de lazer como shopping e cinemas, apesar de a escola estar localizada bem próxima do bairro Estrela Sul, que conta com dois shoppings, implementados por motivação de construções de condomínios de alto padrão (MONTEIRO, 2014).

Tal fato corrobora o estudo de Nascimento et al., (2015) que apontam os shoppings como espaços de segregação social no contexto urbano, que implicitamente deveria ser restrito a apenas determinada parcela da sociedade para ser considerado um espaço valorizado, seguro e que conferiria distinção social, reforçando o distanciamento dos negros e brancos no Brasil.

\section{b) Vídeo e música sobre o racismo no Brasil}

Posteriormente ao jogo do privilégio branco, foi apresentado aos alunos um vídeo do canal Nerdologia ${ }^{6}$. Trata-se de um o canal brasileiro de divulgação científica com maior número de inscritos (mais de 1.400.000), que possui um selo de qualidade para divulgadores científicos, garantindo que o conteúdo veicula informações científicas sérias, com fontes reconhecidas e representativas do consenso científico (CARVALHO, 2016).

O vídeo escolhido foi "A origem da Escravidão no Brasil” que explica de forma prática e simples (Figura 3), com algumas ilustrações e esquemas a contraposição da escravidão na Antiguidade e a escravidão no Atlântico, sendo a primeira baseada na

${ }^{6}$ https://www.youtube.com/nerdologia 
apropriação de escravos por caráter de guerras religiosas, e a segunda baseada no componente étnico, criando uma estrutura racial, e por causa de traços fenotípicos como a cor da pele, formato do nariz, da boca, cabelo e também comportamentos, que eram vistos como selvagens e primitivos existe um povo que é considerado escravo, e isso é herdado pelos seus filhos perpetuamente.

Assistir sobre a escravidão despertou nos alunos um sentimento de reflexão que gerou um debate, em que muitos deles se chocaram com a realidade que muitas pessoas viveram durante centenas de anos.

FIGURA 3: Alunos posicionados para a atividade.

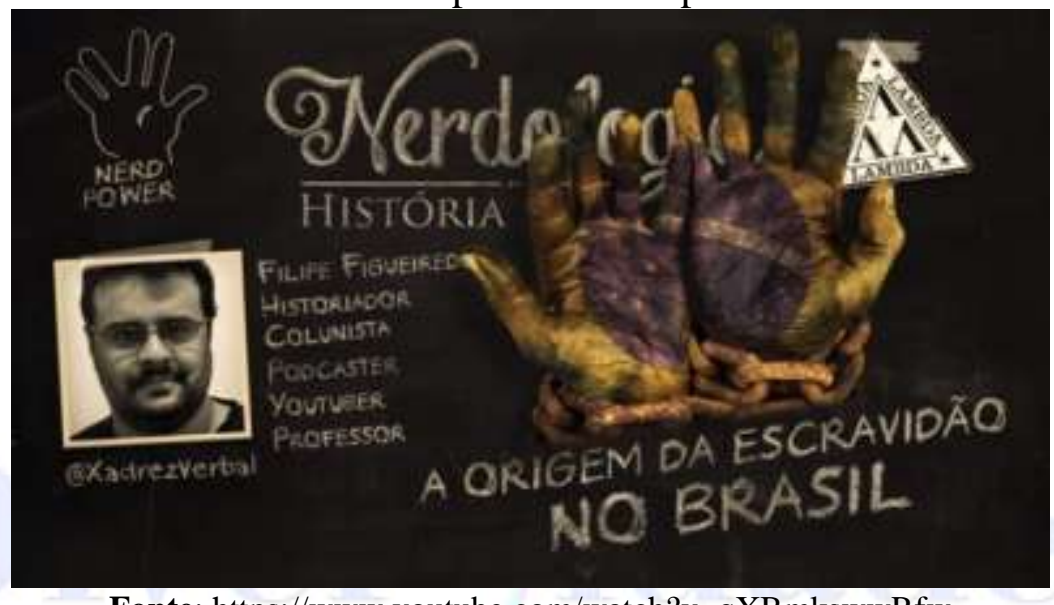

Fonte: https://www.youtube.com/watch?v=qXBmkswwRfw

Outro recurso utilizado para instigar os alunos e as alunas a refletirem e questionarem a respeito do tema abordado foi a música, tentando mostrar que as aulas de geografia são capazes subsidiar questões presentes no cotidiano e fazem parte do espaço em que estão inseridos.

A música escolhida é intitulada "Deixa o meu cabelo", de autoria do cantor de rap Delacruz, interpretada pelo grupo de samba Bom Gosto. Versa sobre representatividade, sobre o cabelo afro ou não, sobre o direito de usar sem ser criticado, deixando claro que "bom" ou "ruim" não é adjetivo para cabelo. Cabelo é ondulado, liso, afro, black, cacheado, mas bom ou ruim não, porque é cabelo. Segue abaixo um trecho da letra da música:

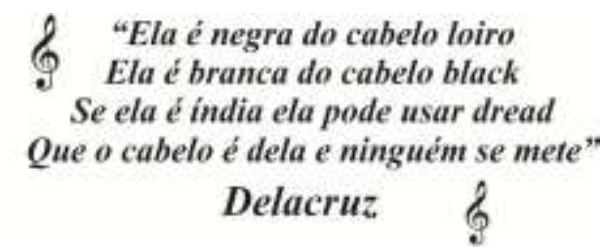


Trotta e Santos (2012) chamam atenção para a música como manifestação coletiva, capaz de compartilhar ideias, valores, crenças e modos de pertencimento, o que envolve disputas, conflitos e negociações sociais, e que compositores negros, por vezes, conseguem transmitir as tensões relacionadas ao racismo.

Ao ouvirem a música, foi perceptível boa recepção dos estudantes, pois muitos já conheciam, no entanto não haviam escutado da forma crítica o que a música propõe. Havendo uma contextualização e, consequente, ressignificação da música para eles. Durante a atividade uma aluna, com seu cabelo crespo, os soltou, demonstrando estar mais segura quanto às suas características, no momento que ouviu o trecho " $\mathrm{O} \mathrm{meu}$ cabelo é expressão real de quem sou". Na escola há vários alunos que já utilizavam o cabelo crespo black, relembrando os grandes movimentos culturais de beleza negra, no entanto, para além da estética, a atividade ser propôs, como nos traz Santos e Santos (2018), na influência e em estratégias de luta contra o racismo para, como parte de um contexto maior de desbranqueamento da moda e da beleza no Brasil.

Para consolidar as discussões geradas durante a atividade, os Pibidianos propuseram que os estudantes fizessem ilustrações com frases ou quadrinhos, que refletissem o que desejariam expressar como resultados das reflexões sobre o preconceito e a escravidão (Figura 4).

FIGURA 4: Ilustrações dos estudantes do sexto ano.

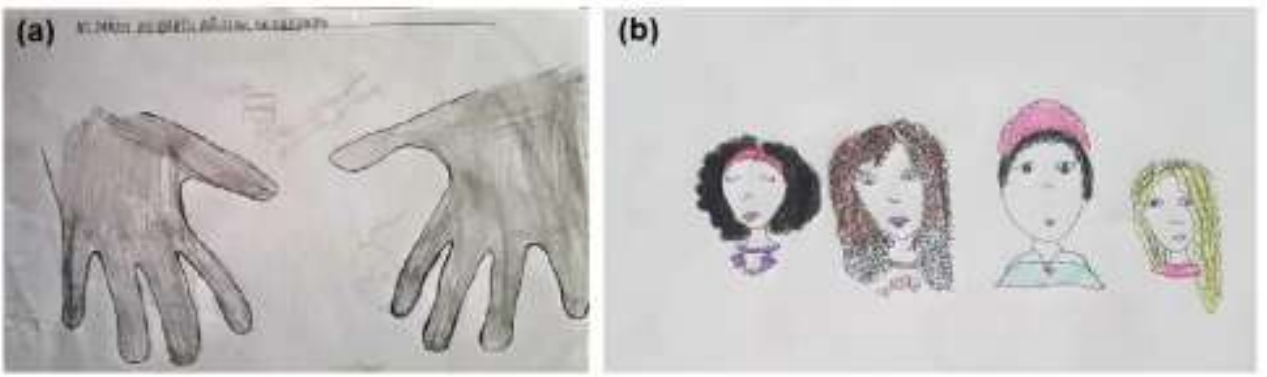

Fonte: Os autores, maio de 2019.

A figura 4a mostra um desenho feito por um dos alunos e na parte superior da imagem está escrito "As mãos do Brasil não serão acorrentadas”. A quebra das correntes, que simbolizam justamente a escravidão, somada a frase trazida pelo estudante, podem ser interpretadas como uma reflexão sobre um caráter libertador e consciente de que não há mais espaço e justificativas para o preconceito. Cabe ressaltar, que compreendemos o desenho do discente, contudo é necessário conhecer a história da ancestralidade dos povos africanos, que foram trazidos forçadamente para o Brasil, buscando desassociar o negro e as correntes, uma vez que os povos africanos 
escravizados possuíam uma história, línguas, vestimentas, organização social. Entretanto, esse trabalho desenvolve-se de maneira ainda introdutória, reconhecendo, portanto esse desenho como um tema gerador de aprofundamento de discussões e da temática dos povos africanos.

Já na figura $4 b$, o estudante mostra pessoas com cabelos diferentes, todos com o mesmo destaque na ilustração, transmitindo a ideia das atividades que era de promover uma percepção de diversidade étnica-racial.

\section{c) Quiz do racismo}

Como meio de avaliação das práticas descritas anteriormente, foi realizado um levantamento sobre a visão geral das turmas, por meio de um questionário (Quadro 2) que foi intitulado "Quiz do Racismo", no qual os estudantes responderam de forma anônima. As perguntas foram pensadas e adaptadas, por todos os Pibidianos, tomando como base leituras científicas, sites e blogs sobre ativismo negro a fim de criar um parâmetro sobre o impacto que as atividades poderiam estar trazendo para os estudantes.

Quadro 2: Quiz do racismo.

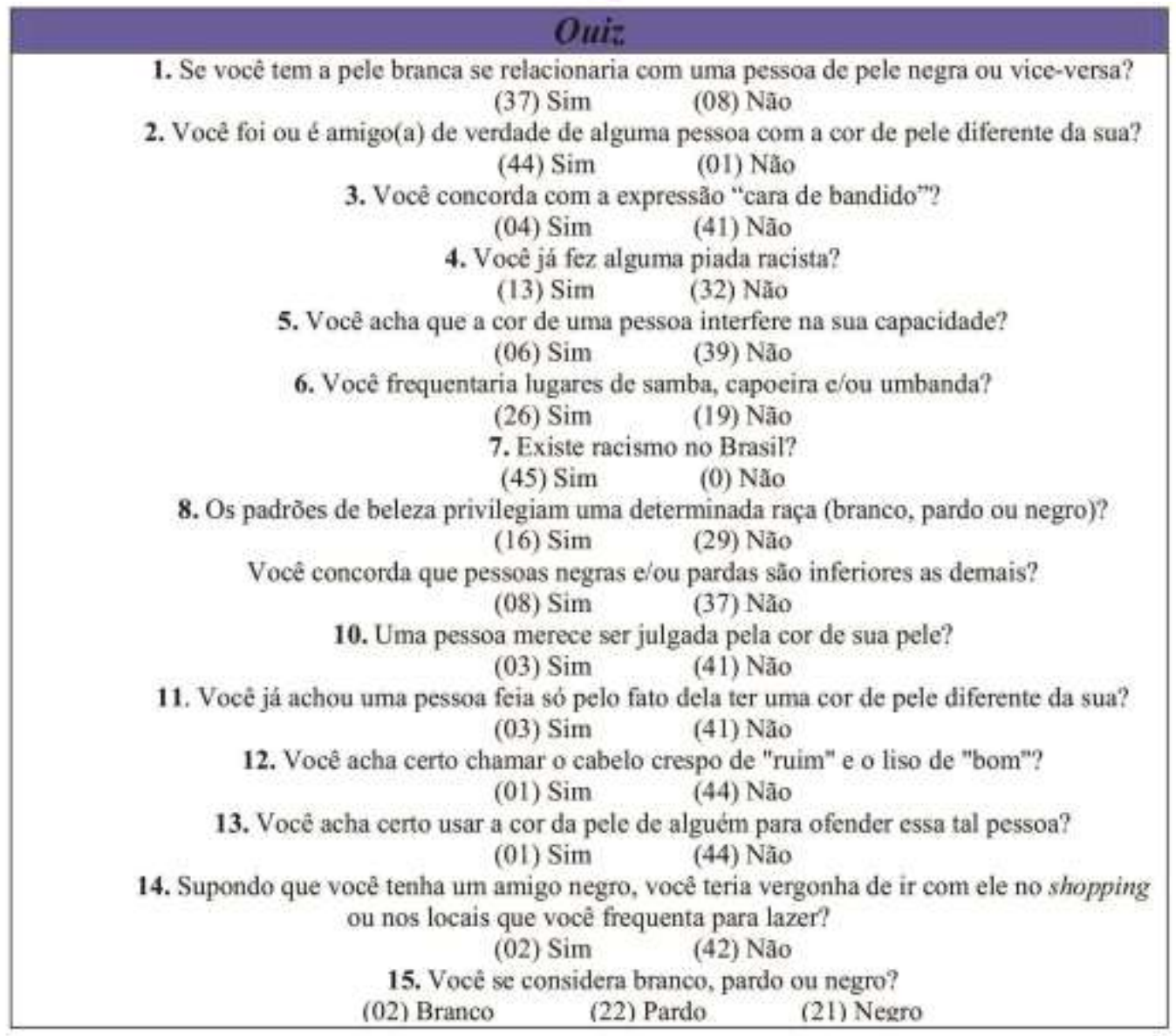

Fonte: Os autores, maio de 2019. 
Ao analisarmos as respostas, pode-se perceber que a maioria dos estudantes já não banaliza mais as situações racistas, pois foram alguns comportamentos trazidos em algumas perguntas do quiz que motivou os Pibidianos a construírem um arsenal de atividades que tratassem do tema.

Chama-nos a atenção, positivamente, a resposta categórica e unânime sobre a existência do racismo no Brasil, já que Silva; Santana; Silveira (2020) nos alerta sobre o perigo do negacionismo por meio discurso oficial e reproduzido por parte da sociedade, podendo comprometer os canais de reflexão e de crítica socioeconômica e cultural, tirar autonomia dos indivíduos, e os deixando sob uma ingenuidade político/ideológica.

Em contrapartida, ao serem questionados sobre frequentarem lugares de samba, capoeira e/ou umbanda, as respostas foram equilibradas pois $42,2 \%$ dos estudantes afirmaram que não frequentariam tais ambientes. Willeman e Lima (2010) já sinalizavam para um avanço na reparação aos danos causados à população negra ao longo da história do Brasil, mas afirmam que muito ainda precisa ser feito para desconstruir a herança do Brasil colonial, onde africanos trazidos forçadamente na condição de escravos eram impedidos de cultuar suas deidades, suas características culturais eram cerceadas e até mesmo criminalizadas, como no caso da capoeira.

Oliveira et al. (2010) relatam que até entre as primeiras organizações de lutas contra o racismo no Brasil na década 1930, ainda persistiam ideologias que não viam propriamente com bons olhos as expressões culturais que remetessem a uma origem africana, tais como o samba, a capoeira e o candomblé, pelo contrário, percebiam nelas um resquício da inferioridade do negro diante do branco.

Diante disso, se vislumbra que a tais discussões precisam ser amplamente discutidas e que a escola é uma das instâncias socioculturais pertinentes para a reflexão dos negros no Brasil, para que a reprodução de frentes racistas seja cada vez mais combatida.

\section{Considerações finais}

Ao fim de quase dezoito meses do Pibid e inúmeras atividades que perfizeram pelos três eixos educacionais (ensino, pesquisa e extensão) destaca-se a importância da atuação propositiva dos Pibidianos, que souberam integrar o espaço orgânico da escola com a esfera acadêmica da universidade. 
Foi percebido um avanço e amadurecimento nas reflexões dos estudantes dos sextos anos sobre a temática da equidade racial na escola, além da promoção de uma discussão mais ampla sobre o tema do racismo atrelado à construção do espaço geográfico, no qual emergiram como sujeitos e protagonistas desta construção.

Outro fator positivo foi que as intervenções do projeto foram feitas no início dos anos finais do ensino fundamental prevendo a inserção de temáticas mais complexas, e ao mesmo tempo, que os estudantes adquiram mais maturidade, criticidade e consciência da realidade dos processos históricos, políticos e sociais do país e seus reflexos sobre espaço vivido, buscando entendimento sobre o papel de cada um no contexto da construção de uma sociedade que supere uma herança racista desigual.

\section{Agradecimentos}

Os autores agradecem à CAPES pela concessão de Bolsas de Iniciação à Docência, Supervisão e Coordenação de Área, no Programa Institucional de Bolsas de Iniciação à Docência no período de 2018 a 2020.

\section{Referências}

ALMEDA, S. L. Racismo Estrutural. São Paulo: Produção Editorial Pólen LTDA, 2019. $256 \mathrm{p}$.

ANUNCIAÇÃO, D.; TRAD, L. A. B.; FERREIRA, T. “Mão na cabeça!”: abordagem policial, racismo e violência estrutural entre jovens negros de três capitais do Nordeste. Saúde e Sociedade, v. 29, p. 1-13, 2020.

BRASIL. Estatuto da igualdade racial: Lei no 12.228, de 20 de julho de 2010, e legislação correlata. 3. ed. Brasília: Câmara dos Deputados, Edições Câmara, 2014. 120 p.

BRASIL. [Constituição (1988)]. Constituição da República Federativa do Brasil. Texto constitucional promulgado em 5 de outubro de 1988. Brasília, DF: Senado Federal, [2016]. 496 p.

BRASIL. Ministério da Educação. Base Nacional Comum Curricular: Educação é a Base. 20 dez. 2017. Disponível em: http://basenacionalcomum.mec.gov.br/images/BNCC_20dez_site.pdf. Acesso em agosto de 2019.

CARVALHO, M. C. Divulgação científica no Youtube: narrativa e cultura participativa nos canais Nerdologia e Peixe Babel. In: XXXIX Congresso Brasileiro de 
Ciências da Comunicação-Intercom, 2016, São Paulo. Anais... XXXIX Congresso Intercom, 2016.

COELHO, W. N. B.; COELHO, M. C. Os conteúdos étnico-raciais na educação brasileira: práticas em curso. Educar em Revista, p. 67-84, 2013.

FERREIRA, W. B. O conceito de diversidade no BNCC Relações de poder e interesses ocultos, Revista Retratos da Escola, Brasília, v. 9, n. 17, p. 299-319, jul./dez. 2015.

FREIRE, P. Pedagogia do Oprimido, Rio de Janeiro, Paz e terra ed. 17, 107 p.1987.

FREIRE, P. Educação como prática da liberdade. 20.ed. Rio de Janeiro, Paz e Terra, 1983. $157 \mathrm{p}$.

GOMES, N. L. Trajetórias escolares, corpo negro e cabelo crespo: reprodução de estereótipos ou ressignificação cultural? Revista Brasileira de Educação, Belo Horizonte, n.21, p. 40-51, 2002.

HESS N. Teaching Large Multilevel classes. Cambridge University Press, UK. Hess, Teaching Large Multilevel classes, Cambridge University Press, UK, 2001.

IBGE. Pesquisa Nacional por Amostra de Domicílios Contínua. 2018. Disponível em: https://biblioteca.ibge.gov.br/visualizacao/livros/liv101657_informativo.pdf. Acesso em setembro de 2019.

Pesquisa nacional por amostra de domicílios: síntese de indicadores 2015 / IBGE, Coordenação de Trabalho e Rendimento. - Rio de Janeiro: IBGE, 2016. 108p

JACCOUD, L. O combate ao racismo e à desigualdade: o desafio das políticas públicas de promoção da igualdade racial. In: THEODORO, Mário. (Org.). As políticas públicas e a desigualdade racial no Brasil: 120 anos após a abolição. 1ed.Brasília: IPEA, 2008, v. 1, p. 131-166.

LINS, S. L. B.; LIMA, A. V.; CAMINO, L. O Papel dos Valores Sociais e Variáveis Psicossociais no Preconceito Racial Brasileiro. Psicologia e Sociedade (Impresso), v. 26, p. 95-105, 2014.

MALACHIAS, A. C. Geografia e Relações Raciais: Desigualdades Sócio-Raciais em Preto e Branco. Dissertação de Mestrado em Geografia Humana, Universidade de São Paulo. 2006. 124 p.

MARQUES, R. Por uma perspectiva espacial da escola. Revista Brasileira de Ensino em Geografia, v. 3, p. 5-20, 2013.

MONTEIRO, G. L. Tinha uma pedra no meio do caminho, no meio do caminho tinha uma pedra. O Bairro Dom Bosco: uma longa vida comunitária e seus desafios frente ao avanço do capital imobiliário. Dissertação de Mestrado, Programa de Pós-Graduação em Geografia, Universidade Federal de Juiz de Fora. 2014. 224 p. 
NASCIMENTO, M. C. R.; OLIVEIRA, J. S.; TEIXEIRA, J.C.; CARRIERI, A. P. Com que Cor eu vou pro Shopping que você me convidou? RAC Eletrônica, v. 9, p. 245$268,2015$.

OLIVEIRA, A. P.; WEY, B.; SANDER, C.; BASTOS, J. V.; FELIX, J. Batista J.; AMANCIO, J. M.; UTLEICH, L. C.; PERIUS, O.; NOVELLI, P. G. A.; SCHORN, R. As Primeiras Formas de Lutas Contra o Racismo no Brasil Republicano. Tempo da Ciência (Unioeste), v. 16, p. 67-80, 2010.

OLIVEIRA, I. M. A. A Questão Racial Na Escola, Universidade Estadual Norte do Paraná 2011.

SANTOS, A. P. M. T.; SANTOS, M. R. Geração Tombamento e Afrofuturismo: a moda como estratégia de resistência às violências de gênero e de raça no Brasil. Dobras (BARUERI, SP), v. 11, p. 157-181, 2018.

SANTOS, R. E. Refletindo sobre a Lei 10.639: possibilidades e necessidades do ensino de Geografia a partir de um tensionamento do Movimento Negro, Rio de Janeiro, Universidade do Estado do Rio de Janeiro, 2009.

SANTOS, R. E. O ensino de Geografia do Brasil e as Relações raciais: reflexões a partir da Lei 10.639. "Diversidade, Espaço e Relações Étnico-Raciais: o Negro no Ensino de Geografia”. Belo Horizonte: Ed. Autêntica, 2007.

SANTOS, C. O ensino de geografia e a cultura africana e afro-brasileira na escola. Revista de Educação Ciência e Tecnologia, Canoas, v.3, n.1, 2014.

SILVA, A. L.; SANTANA, W. K. F.; SILVEIRA, E. L. O samba-enredo no Ensino de História do Brasil, Educação antirracista e decolonial: "Meu Deus, meu Deus, está extinta a escravidão?". Educação: entre saberes, poderes e resistências. Vol. I. 596 p.. 1ed.São Carlos, SP: Pedro \& João Editores, 2020, v. 1, p. 52-79.

SILVA, G.; ARAÚJO, M. Da interdição escolar às ações educacionais de sucesso: escolas dos movimentos negros e escolas profissionais, técnicas e tecnológicas. In: ROMÃO, J. (Org.). História da educação dos negros e outras histórias. Brasília/DF: Ministério da Educação, 2005.

SILVA, C. I. R.; SOUZA, H. T.; LOURES, L. P.; ANDRADE, L. B.; SANTOS, G. B. O ensino de Geografia e as relações étnico-raciais na escola. Educação Pública, v. 20, n. 21,9 de junho de 2020 .

SOUZA, E. A. A Lei no 10.639/2003: uma experienciação no quilombo e em uma escola pública de Porto Alegre. 2009. 174 f. Dissertação (Mestrado em Educação) Universidade Federal do Rio Grande do Sul. Porto Alegre, 2009.

TRINDADE, A. L. O racismo no cotidiano escolar. Dissertação (Mestrado). Fundação Getúlio Vargas Instituto de Estudos Avançados em Educação Departamento de Psicologia da Educação, 2002. 
TROTTA, F. da C., SANTOS, K. J. F. P. Respeitem meus cabelos, brancos: música, política e identidade negra. Revista FAMECOS, 19(1), p. 225-248, 2012.

WILLEMAN, E. M.; LIMA, G. O preconceito e a discriminação racial nas religiões de matriz africana no Brasil. Revista UNIABEU. Tecnologia, v. 3, p. 71-99, 2010.

Recebido em setembro de 2020.

Aprovado em dezembro de 2020. 